\title{
Tuberculosis in Nunavut: looking back, moving forward
}

\author{
Pamela Orr MSc MD
}

$\mathrm{T}$ he history of tuberculosis in Nunavut is not one of a century of failure..$^{1,2}$ Rather, it is a story of success, followed by failure. In the 1950s, the annual incidence of tuberculosis among Inuit in Canada and Alaska was 15002900 cases per 100000 population, but it fell rapidly to a nadir of 31 per 100000 in 1997 among Canadian Inuit and 21 per 100000 in 2002 among Alaskan Natives. ${ }^{1,3,4}$ However, tuberculosis among Canadian Inuit has dramatically increased since 1997. In 2010, the incidence in Nunavut, where more than $80 \%$ of the population is Inuit, was 304 per 100000 - more than 66 times the rate seen in the general Canadian population (4.6 per 100 000). ${ }^{5}$ In contrast, the incidence among Alaskan Natives in 2010 was 33 per 100000 - about 3.5 times the rate seen in the general Alaskan population. ${ }^{4}$

How did this happen? Both Canada and Alaska initially employed programs that involved active case-finding and admission to southern sanitaria. However, Alaska brought care close to home by training local health aides who supervised tuberculosis care in remote communities and establishing state hospitals, whereas Canada relied primarily on nurses sent north and evacuating patients to southern hospitals. ${ }^{3}$ In 1955 , Alaska began testing and subsequently implemented isoniazid prophylaxis for people with latent tuberculosis infection. ${ }^{3}$ An intensive mass campaign was not fully implemented in the Canadian arctic until the late 1960s. Under the leadership of Dr. Stefan Grzybowski, both latent and active cases were treated; follow-up and tracking were relentless. The subsequent $15 \%$ annual decrease in the incidence of tuberculosis was greater than any previously recorded decline in the epidemiology of the disease, and one that occurred despite the ongoing prevalence of adverse social determinants. ${ }^{1,6}$

In the late 1970s, Grzybowski's intense mass campaign gave way to the integration of tuberculosis management into the routine programs at northern health centres. The epidemiologic picture had changed from high prevalence of active disease to decreasing overall incidence of disease, with periodic community outbreaks. Case contacts often included many members of a community, given the closeness of social inter- action. Each community epidemic infected new generations of children, sowing the seeds for reactivation disease in adults a decade later. The program for early identification and therapy of contacts, and other people with latent infection at high risk for progression to disease, has not kept up.

Integrating both public health and acute care in the Canadian North is challenging. Acute health needs are intense as the population grows rapidly, the incidence of chronic disease increases and the incidence of infectious diseases remains high. The "tyranny" of acute care siphons attention, time and energy from prevention activities. The social determinants of tuberculosis in Grzybowski's day, including crowded and poorly ventilated housing, poverty, low levels of education, barriers to accessing adequate health care and malnutrition, are still prevalent. In addition, the challenges to tuberculosis control in Nunavut today include the inadequate number and training of health personnel; inadequate computer health information systems; reliance on southern hospital, laboratory and consultant services; and cultural and historical barriers to early diagnosis and care, including fear based on historic and current traumatic experiences of dislocation, alienation, stigma and racism.

Additional challenges have recently emerged. In 2011, the Public Health Agency of Canada disbanded the Canadian Tuberculosis Committee, along with its Aboriginal Scientific Tuberculosis Subcommittee and the newly proposed Inuit Tuberculosis Subcommittee. In addition, recent national shortages of tuberculin purified protein derivative for tuberculin skin testing, and

\section{KEY POINTS}

- The incidence of tuberculosis in Nunavut is now more than 66 times greater than the rate seen in the general Canadian population.

- Challenges to controlling tuberculosis in Nunavut include the prevalence of social and host determinants of infection and disease, as well as local and national health system barriers.

- The history of tuberculosis in the Canadian North shows us that the disease can be controlled with specific programs.

- Tuberculosis control in Nunavut requires an intensive and appropriately resourced "community-owned" effort that evaluates performance targets and incorporates other creative solutions from circumpolar partners. 
the Bacilli Calmette Guerin (BCG) vaccine have created program challenges at a time of epidemic rates of tuberculosis in Nunavut.

So, what is to be done? Campaigns to reduce tuberculosis require action on the social, economic, political and biomedical fronts. However, in the words of Grzybowski:

One does not have to wait for many decades for socioeconomic development, with higher standard of living. We can control this disease with specific tuberculosis programmes. ${ }^{6}$

It may be argued that intense community programs were effective in the past because of the high rate of adherence among Inuit to the people in authority within a colonial health system. Although barriers to adherence exist today that did not exist in Grzybowski's time, fostering adherence is the responsibility of tuberculosis control programs.

The old tuberculosis principles of "prevent, search, detect, treat" worked in Grzybowski's era, and they work now. Nunavut's Taima TB ("stop tuberculosis") project in Iqaluit focuses on intensive education and involves local Inuit workers in a door-to-door program of detection and treatment of active and latent infection. The evaluation of the project has not yet been published, but its methods encompass the tenets of all successful public health programs: engaging communities at the street level, empowering those in need, removing barriers to care, and being culturally sensitive and relevant.

Intensive control activities should be expanded throughout Nunavut, learning and adapting along the way. Nunavut has great strengths to call upon in this effort. These include a small but dedicated group of health workers, some of whom have many years of experience with tuberculosis management; considerable social cohesion within a society that values trust and reciprocity; and a relatively high degree of awareness of the disease. ${ }^{7,8}$ Nunavut needs to reactivate the community health committees that became dormant and tap into the emerging health activism at the community and organization levels.

Nunavut's strength also lies in its connections and potential partnerships within Canada and with other circumpolar countries. ${ }^{9}$ There is much to be shared and learned. The Northwest Territories has used tracer methods ${ }^{10}$ to evaluate and improve tuberculosis management protocols. Greenland has an integrated biomedical and social approach to tuberculosis, with a review committee consisting of representatives of gov- ernment departments, such as housing and economic development. Alaska is a model in its use of community health aides, performance targets and efficient therapy regimens, such as the newly evaluated short-course (12-week) treatment for latent infection. ${ }^{4}$

An effective, accountable and transparent tuberculosis program, particularly when resources are scarce and under scrutiny, requires performance targets that are regularly evaluated. Such targets have yet to be fully implemented anywhere in Canada, but Nunavut is in the process of piloting draft performance indicators in one community. ${ }^{11}$

One may ask what is so special about tuberculosis, when there are many urgent or emergent health issues in Nunavut. That emphasis on a single illness may dilute action on others is also a concern. However, failure to control an epidemic of a transmissible disease, against which one can do little to protect oneself, is the bigger danger. Tuberculosis is amenable to control through the application of science, as well as social and political will.

\section{References}

1. Grzybowski S, Dorken E. Tuberculosis in Inuit. Ecol Dis 1981; 2:145-8.

2. MacDonald N, Hébert PC, Stanbrook MB. Tuberculosis in Nunavut: a century of failure. CMAJ 2011;138:741-3.

3. Fanning A. Inuit tuberculosis, past and present: When will it end? [abstract W71]. 15th International Congress on Circumpolar Health; 2012 Aug. 5-15; Fairbanks, Alaska.

4. State of Alaska Department of Health and Social Services, Division of Public Health, Section of Epidemiology. Tuberculosis in Alaska 2011 Annual Report. Juneau (Alaska): The Department; 2011. Available: www.epi.hss.state.ak.us/pubs/webtb/TBReport2011.pdf (accessed 2012 Aug. 20).

5. Public Health Agency of Canada. Tuberculosis in Canada 2010, Pre-Release. Ottawa (ON): The Agency; 2012. Available: www.phac-aspc.gc.ca/tbpc-latb/pubs/tbcan10pre/index-eng.php (accessed 2012 Aug. 27).

6. Grzybowski S. Natural history of tuberculosis. Epidemiology. Bull Int Union Tuberc Lung Dis 1991;66:193-4.

7. Duhaime G, Searles E, Usher PJ, et al. Social cohesion and living conditions in the Canadian Arctic: from theory to measurement. Soc Indic Res 2004;66:295-317.

8. Demmer M. The state of tuberculosis in Inuit Nunangat. Ottawa (ON): Inuit Tapiriit Kanatami; 2011. Available: www.itk.ca/sites /default/files/ITK_TB_Report_ENGLISH.pdf (accessed 2012 Aug. 18).

9. Young T.K, Chatwood S. Health care in the North: what Canada can learn from its circumpolar neighbours. CMAJ 2011;183: 209-14.

10. Affleck E. Review of management of the 2007 Yellowknife TB outbreak. Proceedings of the 14th International Congress on Circumpolar Health, 2009. Available: www.circumpolarhealthjournal .net/public/journals/32/CHS_2010_7_ICCH14.pdf (accessed 2013 Jan. 16).

11. Nakajima M, Bourgeois A, Randell E, et al. Developing tuberculosis control program performance indicators in Nunavut, Canada [abstract W71]. 15th International Congress on Circumpolar Health; 2012 Aug. 5-15; Fairbanks, Alaska.

Affiliations: Pamela Orr is with the Department of Medical Microbiology and Community Health Sciences, University of Manitoba, Winnipeg, Man., and the North American Region of the International Union Against Tuberculosis and Lung Disease, New York, NY 